

\title{
Streamlined Synthesis of $\mathrm{C}\left(\mathrm{sp}^{3}\right)$-Rich N-Heterospirocycles Enabled by Visible-Light-Mediated Photocatalysis
}

\author{
Nils J. Floden, ${ }^{\dagger}$ Aaron Trowbridge, ${ }^{\dagger}$ Darren Willcox, ${ }^{\dagger}$ Scarlett M. Walton, ${ }^{\dagger,}{ }^{\ddagger}$ Yongjoon Kim, ${ }^{\dagger}$
}

\author{
and Matthew J. Gaunt ${ }^{*}, \oplus$ \\ ${ }^{\dagger}$ Department of Chemistry, University of Cambridge, Lensfield Road, Cambridge CB2 1EW, U.K. \\ ${ }^{\ddagger}$ Medicinal Chemistry, Oncology, IMED Biotech Unit, AstraZeneca, Cambridge CB4 0WG, U.K. \\ * Supporting Information
}

ABSTRACT: We report a general visible-light-mediated strategy that enables the construction of complex $\mathrm{C}\left(\mathrm{sp}^{3}\right)$ rich $\mathrm{N}$-heterospirocycles from feedstock aliphatic ketones and aldehydes with a broad selection of alkene-containing secondary amines. Key to the success of this approach was the utilization of a highly reducing Ir-photocatalyst and orchestration of the intrinsic reactivities of 1,4-cyclohexadiene and Hantzsch ester. This methodology provides streamlined access to complex $\mathrm{C}\left(\mathrm{sp}^{3}\right)$-rich N-heterospirocycles displaying structural and functional features relevant to fragment-based lead identification programs.

G rowing evidence suggests that an increasing number of aromatic rings in lead compounds can result in greater attrition rates among pharmaceutical candidates due to poor solubility, bioavailability, and pharmacokinetics. ${ }^{1}$ However, libraries of lead-like structures often comprise compounds with predominantly $\mathrm{C}\left(\mathrm{sp}^{2}\right)$-rich scaff olds. Consequently, the assessment of structurally distinct libraries of $\mathrm{C}\left(\mathrm{sp}^{3}\right)$-rich small molecules displaying diverse polar functionality could help to identify new lead candidates in fragment-based screening approaches that may exhibit enhanced physical and biological properties. ${ }^{2}$ In considering the design of novel $\mathrm{C}\left(\mathrm{sp}^{3}\right)$-rich small molecules for fragment-based approaches, ${ }^{3}$ it is noticeable that conformationally restricted scaff olds show highly reproducible results in in silico screening programs; the well-defined spatial orientation of molecular features in a candidate compound often leads to increased binding affinities. One approach toward limiting structural flexibility within $\mathrm{C}\left(\mathrm{sp}^{3}\right)$-rich small molecules is through the introduction of a spirocycle. ${ }^{4}$ In comparison to aromatic scaff olds, fine-tuning the structural and functional features in these frameworks off ers an alternative means through which to probe interactions with target binding sites by varying ring size,

adjusting electronic properties, and manipulating substituent eff ects. ${ }^{5}$ As a result, spirocyclic motifs displaying polar functionality are emerging in pharmaceutical agents and lead compounds (Figure 1a). ${ }^{4}$

Despite the attractive properties offered by rigid saturated polar spirocyclic scaffolds, access to diversely functionalized variants mainly relies on multistep alkyl- and acylative methods. ${ }^{5}$ Notable advances on these approaches include dearomatization-based strategies, using $\mathrm{Pd}$, Ir, or Fe catalysts, ${ }^{6-{ }^{c}}$ which harness the intrinsic reactivity of tethered (hetero)arene building blocks for the generation of a selection of spirocyclic N-heterocycles (a)
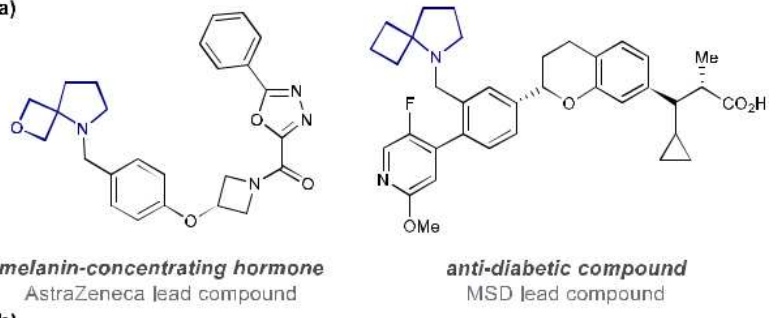

(b)

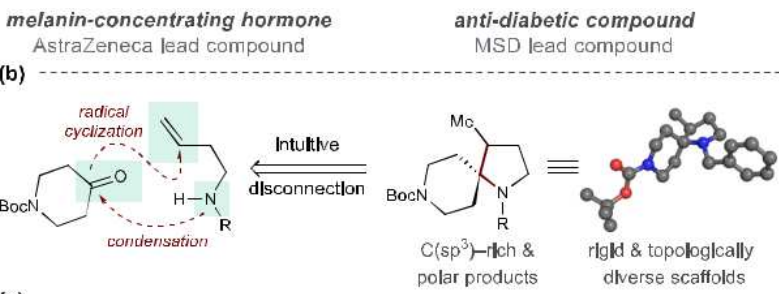

(c)
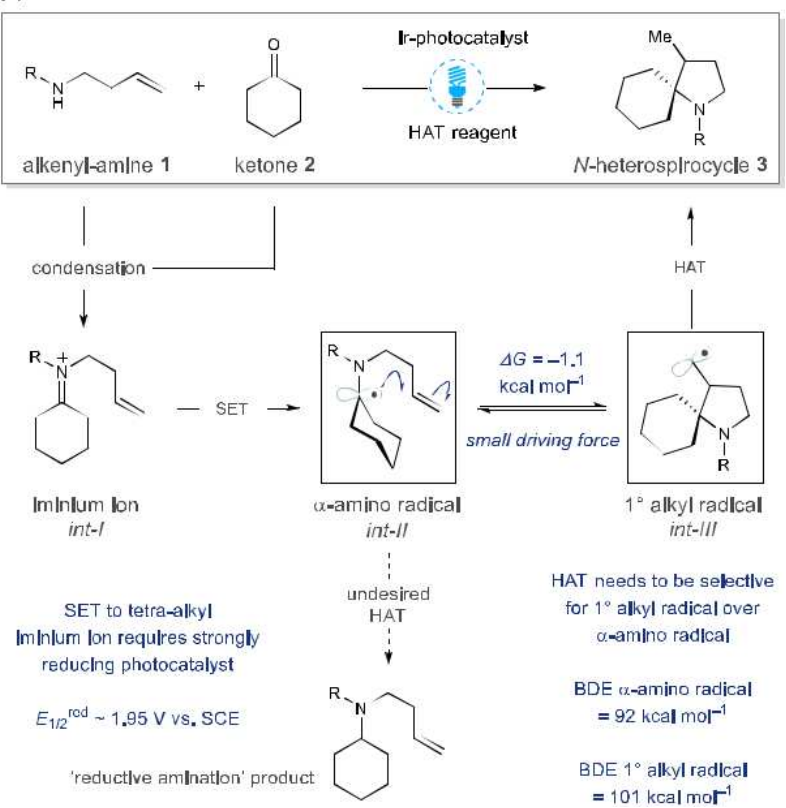

Figure 1. Evolution of the cyclization strategy. Gibbs free energy calculated by DFT methods (UPW6B95-D3BJ/def2-QZVP). Hydro-gens removed for clarity.

with different ring sizes. Bode and co-workers produced a range of spirocyclic N-heterocycles using their SnAP technology; ${ }^{6 d, e}$ 
iminium ion formation between amino-stannane reagents and cyclic ketones enables a stoichiometric copper(II) cyclization to access free $(\mathrm{NH})$-secondary amino-spirocyclic products. To complement these approaches, we reasoned that a photocatalytic strategy ${ }^{7}$ based on an intuitive retrosynthetic disconnection of tertiary amine-based $\mathrm{N}$-heterospirocycles directly to feedstock ketones and readily available alkenyl-derived secondary amines could be realized through the intermediacy of an $\alpha$-amino radical (Figure 1b). ${ }^{8}$ The structurally distinct $\mathrm{C}\left(\mathrm{sp}^{3}\right)$-rich polar $\mathrm{N}$ heterospirocycles generated by such a catalytic transformation could be of interest to synthetic and medicinal chemists.

We envisioned that visible-light-mediated photocatalytic single-electron reduction of an alkyl-iminium ion (int-I, Figure 1c), formed from the condensation of a saturated cyclic ketone with a secondary alkylamine, would form a cyclic-tertiary $\alpha$ amino radical (int-II). Addition of this $\boldsymbol{\alpha}$-amino radical to an appended alkene on the amine component would give rise to a substituted pyrrolidine-based spirocyclic scaffold. Recent work from our group established a photocatalytic platform for the addition of nucleophilic $\alpha$-amino radicals (formed from the corresponding iminium ions) to electron-deficient olefins. ${ }^{9}$ Critically, however, a catalytic manifold for the addition of allalkyl-substituted $\alpha$-amino radicals to unactivated alkenes remains an unsolved problem, principally due to the mismatched electronics and low thermodynamic driving force for such a reaction. The lone pair on the nitrogen atom stabilizes the $\alpha$ amino radical but also renders it nucleophilic. Therefore, its addition to an unactivated alkene is polarity-mismatched and produces an alkyl radical (int-III) with no stabilizing substituents that, in turn, can undergo the reverse reaction to re-form the $\alpha$ amino radical via $\mathrm{C}-\mathrm{C}$ bond $\beta$-scission. Indeed, the use of $\mathrm{SmI} 2$, a strong stoichiometric reductant, was required to trap related alkyl radicals via organosamarium intermediates following addition to unactivated alkenes. ${ }^{10}$ However, the metal waste produced in these reactions and frequent need for highly dilute conditions hinder the wider application of this type of process. ${ }^{11} \mathrm{We}$, therefore, questioned whether an alkyl radical could be selectively intercepted in a milder fashion by way of a hydrogen-atomtransfer (HAT) reaction and in preference to HAT to the $\alpha$-amino radical.

Herein, we detail the successful realization of these ideas through the development of a streamlined strategy for the synthesis of complex $\mathrm{C}\left(\mathrm{sp}^{3}\right)$-rich $\mathrm{N}$-heterospirocycles from readily available secondary amines and ketones enabled by visible-light photocatalysis. Keys to the success of this strategy were utilizing a highly reducing Ir-photocatalyst and orchestrat-ing the intrinsic reactivities of 1,4-cyclohexadiene (1,4-CHD) and Hantzsch ester, which facilitated controlled generation and the fate of the radical intermediates present in the reaction. Under optimized conditions, the process combines a range of feedstock aliphatic ketones and aldehydes with alkene-containing secondary amines to forge complex $\mathrm{C}\left(\mathrm{sp}^{3}\right)$-rich N-heterospirocycles displaying structural, functional, and physical features that are likely to be attractive in fragment-based lead identification programs.

We began our investigations by testing reaction conditions based on our previously established photocatalytic process. ${ }^{9}$ Using amine 1a and cyclobutanone (2a) as substrates, $1 \mathrm{~mol} \%$ of $\operatorname{Ir}(\text { ppy })_{3}$, and 2.0 equiv of Hantzsch ester, we were encouraged by the formation of spirocycle $3 \mathrm{a}$ in $30 \%$ yield and only trace amounts of the corresponding reductive amination product (Table 1, entry 1). Following extensive optimization, we found that the use of 1,4-CHD as an additive (entry 2) and a more
Table 1. Selected Optimization Data ${ }^{a}$

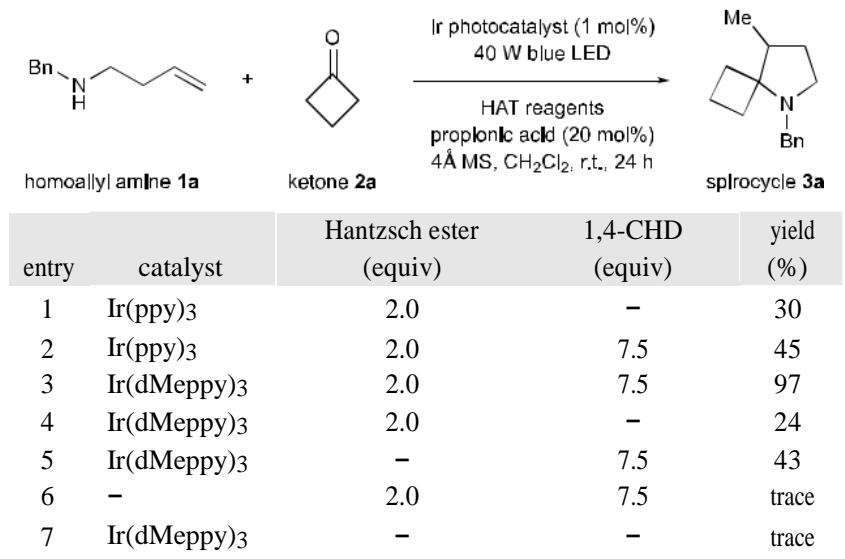

${ }^{\mathrm{a}}$ Reactions employed a $40 \mathrm{~W}$ Blue Kessil lamp, and yields were calculated by GC assay with dodecane as internal standard.

reducing photocatalyst, $\operatorname{Ir}(\mathrm{dMeppy}) 3\left(\left[\mathrm{E}_{1 / 2}{ }^{\mathrm{red}}\left(\mathrm{Ir}^{\mathrm{IV}} /{ }^{\star} \mathrm{Ir}^{\mathrm{III}}\right)\right]=\right.$ $-1.86 \mathrm{~V}$ vs $\mathrm{SCE}$ in $\mathrm{CH}_{2} \mathrm{Cl}_{2}$ ) (entry 3 ), improved the yield to $97 \%{ }^{12}$ We reasoned that the use of $1,4-\mathrm{CHD}$ as a HAT-donor in high concentration would restrict the role of the Hantzsch ester to turning over the $\operatorname{Ir}(\mathrm{IV})$ species formed after singleelectron reduction of the iminium ion, while the more reducing photocatalyst would provide a stronger driving force for the reduction step. A series of control experiments showed that the yield of the reaction dropped to $24 \%$ in the absence of 1,4CHD (entry 4); to $43 \%$ without the Hantzsch ester (entry 5); and to trace amounts without photocatalyst or light or in the absence of both 1,4-CHD and Hantzsch ester (entries 6 and 7).

Having evaluated the reaction conditions, a range of commercially available ketones (Table 2) were reacted to afford $\mathrm{N}$-heterospirocycles $3 \mathrm{a}-3 \mathrm{i}$. Aldehydes also reacted to afford the corresponding pyrrolidines $3 \mathrm{j}-3 \mathrm{~m}$, with the syn-isomer of $3 \mathrm{k}$ being the major diastereomer. The reaction was amenable to heterocyclic ketones, with a series of saturated N-heterocycles readily transformed into rigid, $\mathrm{C}\left(\mathrm{sp}^{3}\right)$-rich, and polar bis-Nheterospirocyclic scaff olds with orthogonal protecting groups on the two nitrogen atoms $(3 n-3 t)$, facilitating further derivatiza-tion. The reaction to form azetidine-derived spirocycle $3 p$ could be performed on a gram scale, even with a reduced catalyst loading of $0.5 \mathrm{~mol} \%$, forming the product in a $63 \%$ yield; the N-groups in $3 \mathrm{p}$ could also be selectively deprotected for further derivatization. ${ }^{13}$ Such derivatives are frequently employed as $\beta$ turn mimetics for GPCR protein binding, where the orthogon-ality of the two nitrogen substituents is key to achieve the desired turncharacteristics. ${ }^{14}$ While the $\operatorname{Ir}(\mathrm{dMeppy}) 3$ photocatalyst had proven optimal for reactions using electron-rich ketones (to form $3 a-3 e$, $3 i, 31$ ), higher yields were observed for electron-deficient ketones (to form $3 \mathrm{f}-3 \mathrm{~h}, 3 \mathrm{j}, 3 \mathrm{k}$, and $3 \mathrm{~m}-3 \mathrm{t}$ ) using the less-reducing $\left[\operatorname{Ir}(\mathrm{dMeppy})_{2}\{\mathrm{dtbbpy}\} \mathrm{PF}_{6}\right.$ photocatalyst.

We next assessed $\mathrm{N}$-substituted alkenylamines $3 \mathrm{u}-3 \mathrm{an}$, where useful functional groups such as sulfonamide, N-Boc-piperidine, heteroaryl motifs $(3 \mathrm{u}-3 \mathrm{ab})$, and a less nucleophilic aniline (3ac) could be built into the spirocycle products. Substitution on the alkene was tolerated (3ad-3ah), introducing valuable functionalities such as the ester and gem-difluoro in useful yields. While no cyclized product was observed from attempts at reacting N-benzyl allylamine (to aff ord azetidine-based spiro-cycles), a piperidine scaff old 3 ai could be assembled via a 6-exo cyclization, further expanding scope of the process. Homoallylic amines containing $\alpha$-substitutents were eff ective in the 
Table 2. Scope of Photocatalytic Synthesis of N-Heterospirocycles
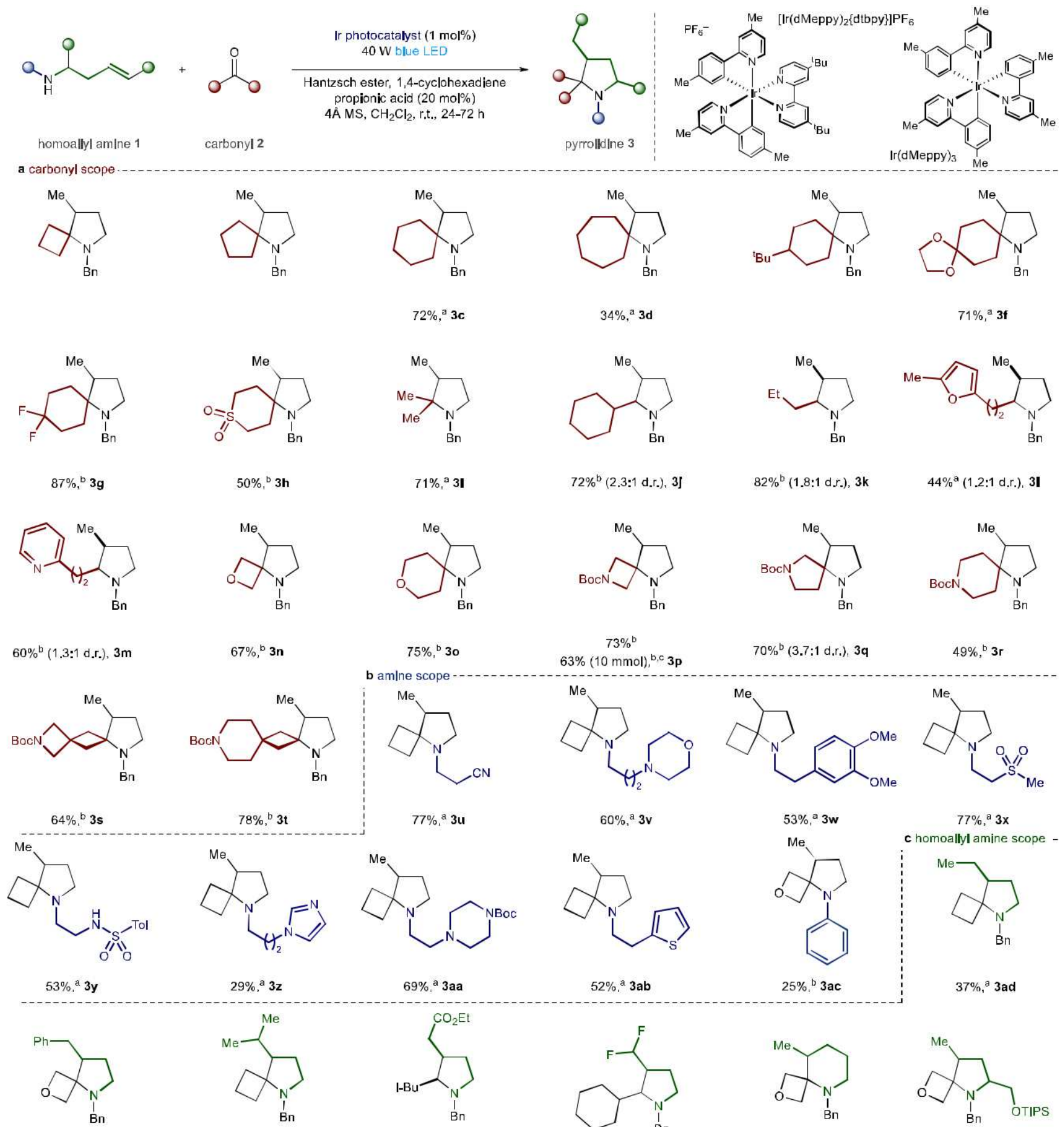

$69 \%,{ }^{a}$ 3aa

$52 \%$, ${ }^{a}$ 3ab
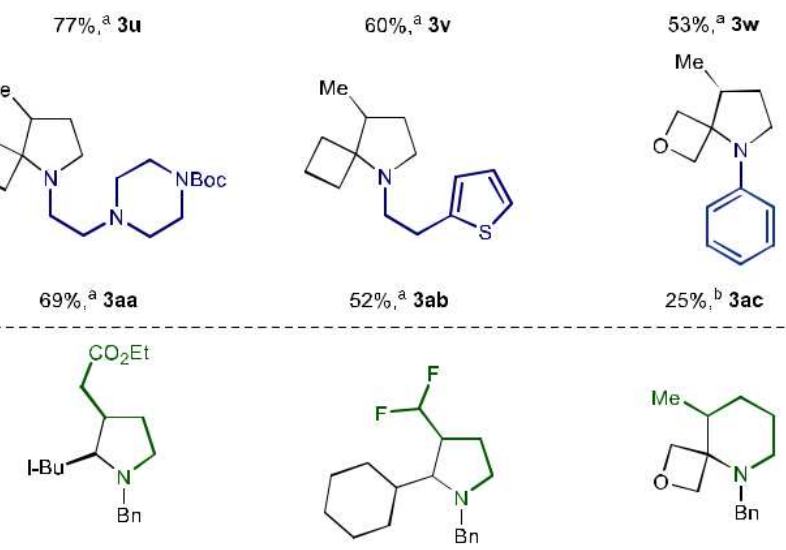

$25 \%{ }^{\text {b }} 3 \mathrm{ac}$

$46 \%^{\mathrm{b}}(1,6: 1$ d.r. $), \mathbf{3 a g}$
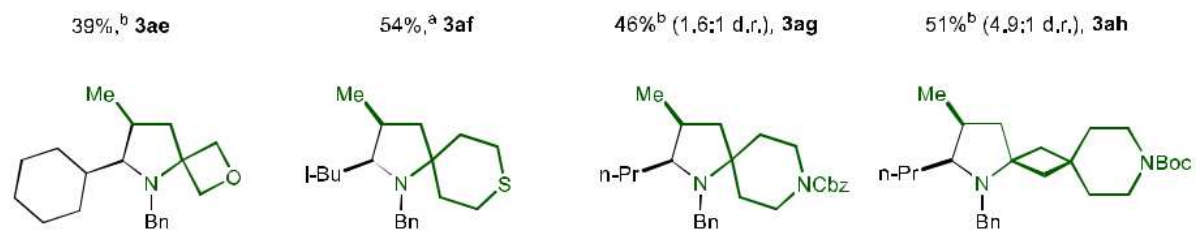

$45 \%^{b}(3: 1 d r), 3 a k$

$80 \%{ }^{b}(1.6: 1$ d.r. $), 3$ al

$65 \%^{b}(>20: 1$ d.r. $), 3 a m$

$78 \%{ }^{\mathrm{b}}(>20 ; 1$ d.r. $)$, 3an<smiles>CC1CCCN(Cc2ccccc2)C12COC2</smiles>

$40 \%{ }^{\mathrm{b}} 3 \mathrm{ai}$

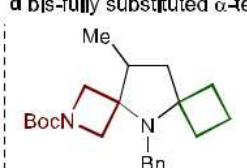

$49 \%,{ }^{b}$ 3ao

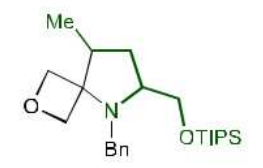

$84 \%{ }^{\mathrm{b}}(1.1: 1$ d.r. $), 3 \mathrm{a}$ J

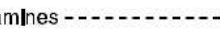

${ }^{\mathrm{a}}$ Reaction using $\operatorname{Ir}(\mathrm{dMeppy}) 3 .{ }^{\mathrm{b}}$ Reaction using $[\mathrm{Ir}(\mathrm{dMeppy}) 2\{\mathrm{dtbpy}\}] \mathrm{PF} 6 .{ }^{\mathrm{c}} 0.5 \mathrm{~mol} \%$ [Ir]. 
cyclization process with both aldehydes and functionalized alicyclic ketones, in some cases with surprisingly high diastereoselectivities $3 a j-3 a n$. We found that the exceptionally hindered spirocycles $3 \mathrm{ao}$ and 3 ap could be accessed in $49 \%$ and $47 \%$ yield respectively, aff ording access to a class of compounds that are challenging to synthesize using classical $\mathrm{C}-\mathrm{N}$ bond-forming methods. ${ }^{6 \mathrm{e}, 15,16}$

Next, we questioned whether we could apply the a-amino radical to a cyclization process with simple alkynes, aff ording $\mathrm{N}$ heterospirocycles carrying a useful alkenyl handle for further functionalization. N-Benzyl-4-aminobutyne derivatives smoothly reacted with a range of cyclic ketones, furnishing the desired spirocycles $4 a-4 g$ in $53-73 \%$ yield (Figure $2 a$ ). Finally,
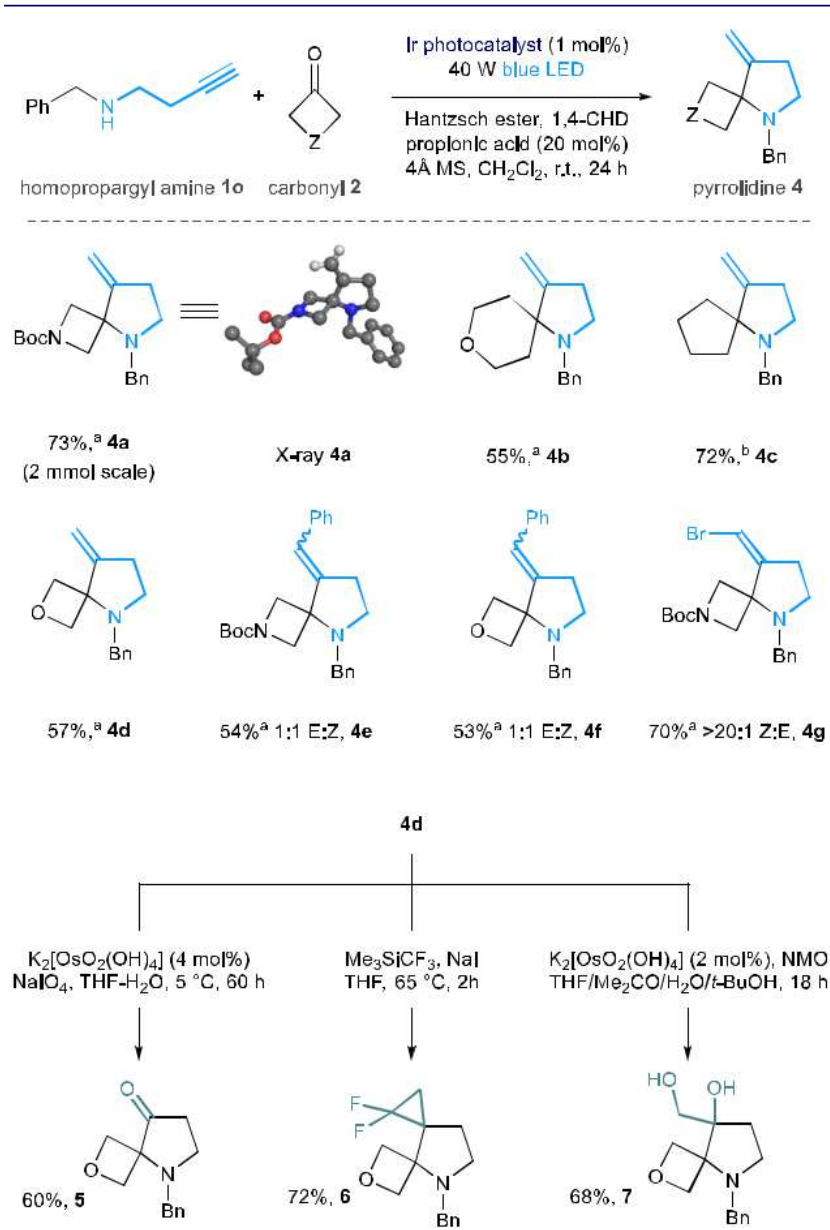

Figure 2. Cyclization on alkynes and amine derivatizations. ${ }^{\mathrm{a}}$ Reaction using $\operatorname{Ir}(\mathrm{dMeppy})_{3} .{ }^{\mathrm{b}}$ Reaction using [Ir(dMeppy) $\left.{ }_{2}\{\mathrm{dtbpy}\}\right] \mathrm{PF}_{6}$.

the alkenyl handle of $4 \mathrm{~d}$ could be derivatized through a difluorocyclopropanation to aff ord 6 in $72 \%$ yield, whose structure comprises three diff erent-sized ring systems and two adjacent spirocyclic centers, as well as different oxidative transformations ( 5 and 7 , Figure $2 b) .{ }^{17}$

We found that the addition of TEMPO, as a radical trap, significantly inhibited the reaction (Figure 3a). A reaction with cyclopropyl-substituted alkenylamine $1 \mathrm{r}$ led to the ring-opened product, supporting the existence of a cyclized radical intermediate (cf. Int-III). Stern-Volmer studies on a representative iminium ion (8) showed effective quenching of the excited state of the $\operatorname{Ir}(\mathrm{dMeppy}) 3$ photocatalyst in comparison to Hantzsch ester (Figure 3c). On the basis of of these studies and those outlined in our optimization (Table 1), we propose a
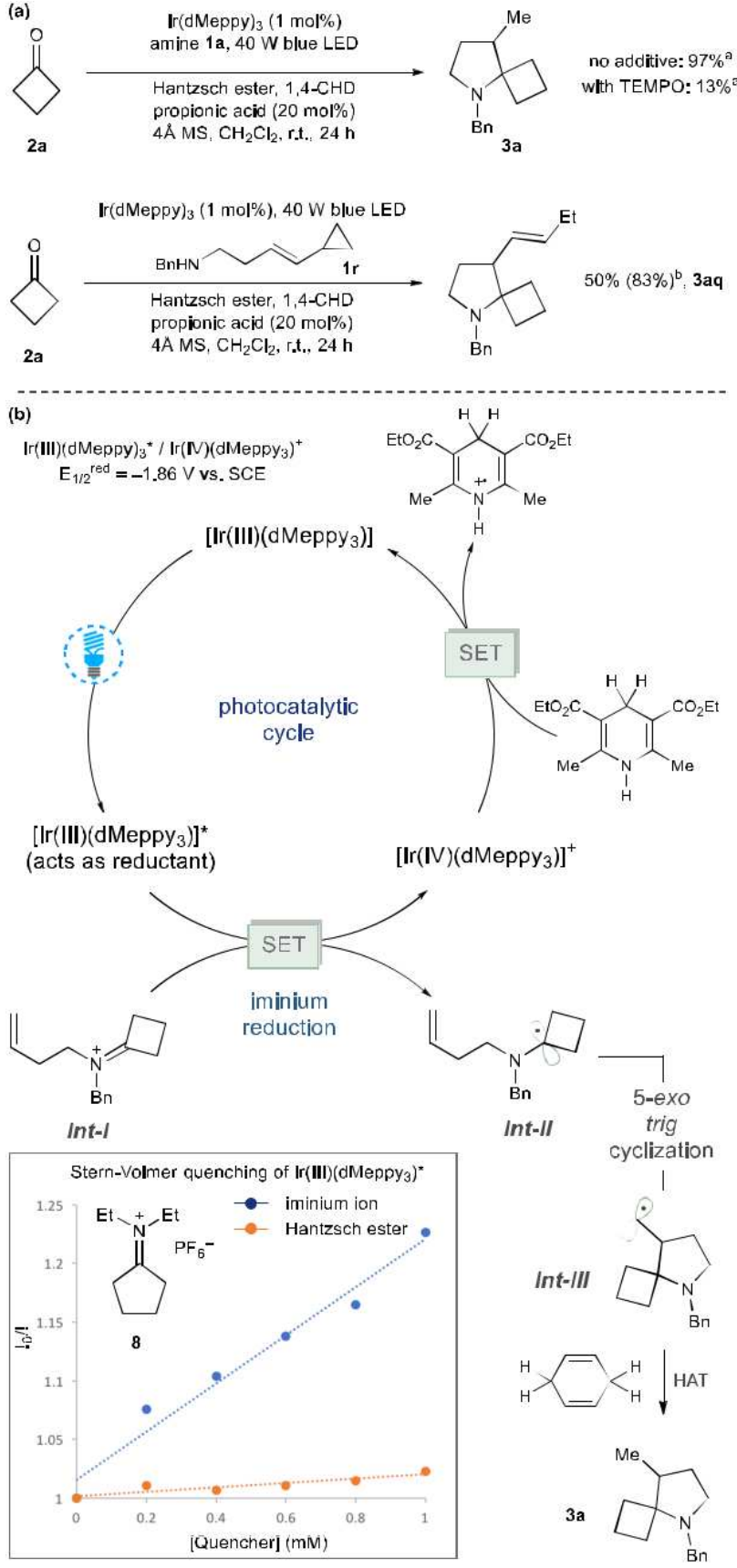

Figure 3. Mechanistic studies. ${ }^{\text {a}}$ Yield determined by GC assay with dodecane as internal standard. ${ }^{b}$ Yield determined by ${ }^{1} \mathrm{H}$ NMR with 1,1,2,2-tetrachloroethane as internal standard.

tentative mechanism for the reaction which begins with visiblelight excitation of $\operatorname{Ir}(\mathrm{dMeppy})_{3}$ to $\operatorname{Ir}(\mathrm{dMeppy}) 3^{*}$ (Figure $3 \mathrm{c}$ ). Single-electron reduction of the iminium ion (Int-I) by $\operatorname{Ir}(\mathrm{dMeppy}) 3^{*}$ forms the $\alpha$-amino radical (Int-II), which engages the pendant alkene in a 5-exo-trig cyclization to form an alkyl radical (Int-III). HAT from 1,4-CHD to the alkyl radical then forms N-heterospirocycle 3. The oxidized $\operatorname{Ir}(\mathrm{IV})(\mathrm{dMeppy}) 3$ species is reduced to the active catalyst by single-electron transfer from the Hantzsch ester, closing the catalytic cycle.

In summary, we have developed a visible-light-mediated process to enable the facile synthesis of heterospirocyclic compounds from readily available starting materials. The photoredox strategy off ers an intuitive retrosynthetic discon- 
nection for difficult-to-access $\mathrm{C}\left(\mathrm{sp}^{3}\right)$-rich $\mathrm{N}$ heterospirocyclic scaffolds that may be of interest to practitioners of both synthetic and medicinal chemistry.

\section{ASSOCIATED CONTENT}

\section{* Supporting Information}

Experimental procedures and spectral data (PDF)

X-ray crystallographic data for 6 (CIF)

$\mathrm{X}$-ray crystallographic data for $4 \mathrm{a}(\mathrm{CIF})$

\section{AUTHOR INFORMATION}

Corresponding Author

*mjg32@cam.ac.uk

ORCID

Matthew J. Gaunt: 0000-0002-7214-608X

Notes

The authors declare no competing financial interest.

\section{ACKNOWLEDGMENTS}

We are grateful to the Gates Cambridge Trust (N.J.F.) and Herchel Smith Scholarship Scheme (A.T.) for studentships, the EPSRC (EP/S020292/1 and EP/N031792/1), Ambitious Leader's Program, Hokkaido University, Japan (Y.K.), and the Royal Society for a Wolfson Merit Award (M.J.G.). S.M.W. is a Fellow of the AstraZeneca Postdoctoral program. We are grateful to the EPSRC UK National Mass Spectrometry Facility at Swansea University for HRMS analysis.

\section{REFERENCES}

(1) (a) Lovering, F.; Bikker, J.; Humblet, C. Escape from flatland: increasing saturation as an approach to improving clinical success. J. Med. Chem. 2009, 52, 6752-6756. (b) Blakemore, D. C.; Castro, L.; Churcher, I.; Rees, D. C.; Thomas, A. W.; Wilson, D. M.; Wood, A. Organic synthesis provides opportunities to transform drug discovery. Nat. Chem. 2018, 10, 383-394.

(2) Murray, C. W.; Rees, D. C. The rise of fragment-based drug discovery. Nat. Chem. 2009, 1, 187-192.

(3) (a) Fang, Z.; Song, Y.; Zhan, P.; Zhang, Q.; Liu, X. Conformational restriction: an effective tactic in "follow-on"-based drug discovery. Future Med. Chem. 2014, 6, 885-901. (b) Wipf, P.; Skoda, E. M.; Mann, A. Conformational Restriction And Steric Hindrance In Medicinal Chemistry. The Practice Of Medicinal Chemistry; Academic Press: San Diego, 2015; Chap. 11.

(4) (a) Zheng, Y.-J.; Tice, C. M.; Singh, S. B. The use of spirocyclic scaffolds in drug discovery. Bioorg. Med. Chem. Lett. 2014, 24, 36733682. (b) Zheng, Y.-J.; Tice, C. M. The utilization of spirocyclic scaffolds in novel drug discovery. Expert Opin. Drug Discovery 2016, 11, 831-834. (c) Johansson, L.; Anders, M. Azetidine derivatives for treatment of melanin related disorders. Int. Patent WO 2013/011285 A1, 2013. (d) Chen, H.; Colletti, S. L.; Demong, D.; Guo, Y.; Miller, M.; Nair, A.; Plummer, C.; Xiao, D.; Yang, D.-Y. Antidiabetic bicyclic compounds. Int. Patent WO 2016/022742 A1, 2016.

(5) (a) Carreira, E. M.; Fessard, C. T. Four-membered ring-containing spirocycles: synthetic strategies and opportunities. Chem. Rev. 2014, 114, 8257-8322. (b) Rios, R. Enantioselective methodologies for the synthesis of spiro compounds. Chem. Soc. Rev. 2012, 41, 1060-1074.

(c) Singh, F. V.; Kole, P. B.; Mangaonkar, S. R.; Shetgaonkar, S. E. Synthesis of spirocyclic scaffolds using hypervalent iodine reagents. Beilstein J. Org. Chem. 2018, 14, 1778-1805. (d) Melnykov, K. P.; Artemenko, A. N.; Ivanenko, B. O.; Sokolenko, Y. M.; Nosik, P. S.; Ostapchuk, E. N.; Grygorenko, O. O.; Volochnyuk, D. M.; Ryabukhin,
S. V. Scalable synthesis of biologically relevant spirocyclic pyrrolidines. ACS Omega. 2019, 4, 7498-7515.

(6) (a) Rousseaux, S.; Garcia-Fortanet, J.; Del Aguila Sanchez, M. A.; Buchwald, S. L. J. Am. Chem. Soc. 2011, 133, 9282-9285. (b) Zhu, M.; Zheng, C.; Zhang, X.; You, S.-L. Synthesis of cyclobutane-fused angular tetracyclic spiroindolines via visible-light-promoted intramolecular dearomatization of indole derivatives. J. Am. Chem. Soc. 2019, 141, 2636-2644. (c) Adams, K.; Ball, A. K.; Birkett, J.; Brown, L.; Chappell, B.; Gill, D. M.; Lo, P. K. T.; Patmore, N. P.; Rice, C. R.; Ryan, J.; Raubo, P.; Sweeney, J. B. An iron-catalysed C-C bond forming spirocyclization cascade providing sustainable access to new 3D heterocyclic frame-works. Nat. Chem. 2017, 9, 396-401. (d) Siau, W.-Y.; Bode, J. W. One-step synthesis of saturated spirocyclic N-heterocycles with stannyl amine protocol (SnAP) reagents and ketones. J. Am. Chem. Soc. 2014, 136, 17726-17729. (e) Saito, F.; Trapp, N.; Bode, J. W. Iterative assembly of polycyclic saturated heterocycles from monomeric building blocks. J. Am. Chem. Soc. 2019, 141, 5544-5554.

(7) Prier, C.; Rankic, D.; MacMillan, D. W. C. Visible light photoredox catalysis with transition metal complexes: applications in organic synthesis. Chem. Rev. 2013, 113, 5322-5363.

(8) (a) For reviews, see:Zou, Y.-Q.; Xiao, W.-J. Visible light mediated a-amino C-H functionalization reactions; Wiley-VCH: Weinheim, 2018; Chap. 4, pp 93-128. (b) Beatty, J. W.; Stephenson, C. R. J. Amine functionalization via oxidative photoredox catalysis: methodology development and complex molecule synthesis. Acc. Chem. Res. 2015, 48, 1474; Acc. Chem. Res. 2015, 48, 1474-1484. (c) Nakajima, K.; Miyake, Y.; Nishibayashi, Y. Synthetic utilization of $\beta$-aminoalkyl radicals and related species in visible light photoredox catalysis. Acc. Chem. Res. 2016, 49, 1946-1956. For selected examples, see:

(d) McNally, A.; Prier, C.; MacMillan, D. W. C. Discovery of an aamino arylation reaction using the strategy of accelerated serendipity. Science 2011, 334, 1114-1117. (e) McManus, J. B.; Onuska, N. P. R.; Nicewicz, D. A. Generation and alkylation of $\alpha$-carbamyl radicals via organic photoredox catalysis. J. Am. Chem. Soc. 2018, 140, 9056-9060.

(f) Zuo, Z.; Ahneman, D. T.; Chu, L.; Terrett, J. A.; Doyle, A. G.; MacMillan, D. W. C. Merging photoredox with nickel catalysis: coupling of $\alpha$-carboxyl $\mathrm{sp}^{3}$-carbons with aryl halides. Science 2014 , 345, 437-440. (g) Shaw, M.; Shurtleff, J.; Terrett, J. A.; Cuthbertson, J. D.; MacMillan, D. W. C. Native functionality in triple catalytic cross-coupling: $\mathrm{sp}^{3} \mathrm{C}-\mathrm{H}$ bonds as latent nucleophiles. Science 2016 , 352, 1304-1308. (h) Ye, J.; Kalvet, I.; Schoenebeck, F.; Rovis, T. Direct D-alkylation of primary amines enabled by $\mathrm{CO}_{2}$ and electrostatics. Nat. Chem. 2018, 10, 1037-1041.

(9) Trowbridge, A.; Reich, D.; Gaunt, M. J. Multicomponent synthesis of tertiary alkylamines by photocatalytic olefin hydroaminoalkylation. Nature 2018, 561, 522-527.

(10) Aurrecoechea, J. M.; Suero, R. Recent developments in cyclization reactions of A-amino radicals. Arkivoc 2004, xiv, 10-35.

(11) Maity, S.; Flowers II, R. A. Mechanistic study and development of catalytic reactions of Sm(II). J. Am. Chem. Soc. 2019, 141, 3207-3216.

(12) Jung, S.; Kang, Y.; Kim, H.-S.; Kim, Y.-H.; Lee, C.-L.; Kim, J.-J.; Lee, S.-K.; Kwon, S.-K. Effect of substitution of methyl groups on the luminescence performance of Ir ${ }^{\mathrm{III}}$ complexes: Preparation, structures, electrochemistry, photophysical properties and their applications in organic light-emitting diodes (OLEDs). Eur. J. Inorg. Chem. 2004, 2004, 3415-3423.

(13) See Supporting Information.

(14) Bittermann, H.; Bockler,"F.; Einsiedel, J.; Gmeiner, P. A highly practical RCM approach towards a molecular building kit of spirocyclic reverse turn mimics. Chem. - Eur. J. 2006, 12, 6315-6322. (15) Lai, J. Hindered amines. 3,3,5,5-Tetrasubstituted-2oxomorpho-lines and derivatives. Synthesis 1984, 1984, 122-123. (16) Corey, E. J.; Gross, A. W. Methods for the synthesis of chiral hindered amines. J. Org. Chem. 1985, 50, 5391-5393.

(17) Nosik, P. S.; Gerasov, A. O.; Boiko, R. O.; Rusanov, E.; Ryabukhin, S. V.; Grygorenko, O. O.; Volochnyuk, D. M. Gramscale synthesis of amines bearing a gem-difluorocyclopropane moiety. Adv. Synth. Catal. 2017, 359, 3126-3136. 